(Imperial College of Science and Technology, London) of the reasons why London clay assumes a natural. slope of $10 \mathrm{deg}$.

It was noted that very little effort is being devoted to the problem of the stability of excavated slopes. It appears that such slopes are often initially cut at a much steeper angle than is satisfactory for stability, and where large and costly cuttings are required, as, for example, for modern highways, a greater application of the principles of soil mechanies was advocated.

A session of the Conference was devoted to a discussion of earth pressures which determine the stresses acting, for example, on the linings of tunnels and on sheet piling and other earth-retaining structures. It is now recognized that in practice some yield of the structure almost invariably takes place, and the problem is then to make a reliable estimate of the distribution of stresses on structures in terms of this yield. Useful progress on this problem was reported in respect of both sheet piling and tunnels.

The rapid growth of traffic on the roads and the increased weight of aircraft have resulted in the need for thicker and stronger foundations for road and airfield pavements. This has rendered important the need for improved methods of pavement design in order that the most economical approach may be determined with some precision. Although the papers contributed to the Conference were scarcely representative of present thinking on this subject, it appears that reliance is mainly placed on empirical methods of design in which the estimated thickness of pavement is related for particular traffic conditions to the bearing strength of the soil measured by some form of penetration or loaded plate test. However, a trend was noted towards thinking in terms of a design method based on the moduli of deformation of the soil and pavement materials.

An understanding of the factors affecting the moisture conditions in soils under pavements is important because the moisture content largely governs the strength of the soil and hence the design of the pavements. While a satisfactory solution of this problem for humid climates has been developed in terms of the suction properties of the soil, it emerged that the part played by vapour transfer under more arid climatic conditions is not yet fully understood.

Quite apart from the consideration given to the physical properties of soil during the discussion of papers presented in division 1 , the Conference was repeatedly brought back, during the sessions devoted to the more practical problems of foundation engineering, to the need for a better understanding of tho fundamental factors governing these properties. There is now general recognition of the need to express shear strength in terms of effective stresses, and of the importance of making pore water pressure measurements both in laboratory tests and in field studies. These conclusions are, however, of principal value in their practical application to analyses of stability problems and do not help to any great extent in understanding the bases of soil strength.

Perhaps the most encouraging development at this Conference was the emergence of a body of support for the concept that many of the observed shear properties of soils can be satisfactorily explained in terms of internal normal stresses resulting from tensions in the pore water system. It was suggested that the development of this concept may well lead to the shear strength of soil being expressed in terms of a dimensionless coefficient of friction. Papers to the Conference also indicated useful advances in attempts to explain soil properties in terms of colloid chemistry and surface physics. Perhaps it is not too much to hope that by the time the next Conference is held a satisfactory hypothesis will have been developed that explains the part played by tensions in the soil water system and at the same time relates these tensions to the surface forces resulting from the interaction of clay minerals and water.

At the closing session of the Conference, members learnt with deep regret that Prof. Terzaghi had decided to relinquish the presidency of the International Society. The new president is Prof. A. W. Skempton, professor of civil engineering at the Imperial College of Science and Technology, London. It was also learnt that the offices of the Executive Committee had been transferred from Harvard University to the Institution of Civil Engineers in London, with Mr. A. Banister as secretary to the Committee. Paris has been selected as the meeting place for the next international conference.

During the Conference a number of technical visits were arranged to government, university and commercial soil mechanics laboratories and to sites of civil engineering interest. Receptions were held at the Tate Gallery, at the invitation of the chairman and members of the Public Works and Municipal Services Congress and Exhibition Council, and at the Hurlingham Club, and the Conference concluded with a banquet held at Grosvenor House. Following the Conference, many members joined short trips to various parts of the country to see works of civil engineering interest. $\quad$ D. J. MACLEAN

\section{GAS CHROMATOGRAPHY}

$A$

N International Symposium on Gas Chromato. graphy, sponsored by the Analysis Instrumentation Division of the Instrument Society of America, was held at the Kellogg Center for Continuing Education, East Lansing, Michigan, during August 28-30. H. J. Noebels (Beckman Instruments) was general chairman, and the programme was organized by V. J. Coates (Perkin-Elmer Corporation). The meeting was attended by about 350 people. Formal sessions were held in the mornings and evenings, leaving the afternoons free for informal discussions by small groups. This proved to be a very happy arrangement, as it allowed those with special interests to discuss fine points at length without holding up the main proceedings ; I remember in particular a very lively triangular discussion between M. J. E. Golay, A. J. P. Martin and A. I. M. Keulemans on the usefulness of the theoretical plate concept. The formal meetings consisted of invited lectures, followed by a series of short contributed papers.

A large number of papers were concerned with the application of gas chromatography to specific analytical problems, such as arise in connexion with gasolines, ester-type plasticizers, chlorofluorohydrocarbons, glycols and piperazines. Many of the speakers commented on the savings in time and money which the new technique had brought to their companies. Other papers were devoted to detailed 
descriptions of apparatus and accessories (such as sampling devices and integrators), especially in connexion with eommercial gas chromatographic equipment. As it is proposed to publish the full proceedings of the symposium in the near future, this report will be confined to those developments described at the symposium which seem to be of more immediate and general interest.

In the opening lecture, M. J. E. Golay (PerkinElmer) described his theoretical studies on the performance of a simplified gas-liquid chromatographic system, in which the liquid phase was held on the walls of a fine capillary. In such a system there should be no contribution to plate height (or peak spreading) from a channelling or 'eddy' term. Golay showed how the usefulness of such columns could be measured in terms of a 'performance index' (Nature, 180, 435 ; 1957), in which the drop in pressure across the column and the time for analysis are included as the price paid for sharpness of the peak. An account was given of some experimental work which had been undertaken to test the theory. The results were also of great practical interest, in that sharp separations (equivalent to about 10,000 plates) had been obtained with simple columns. Furthermore, it was found possible to run capillary columns extremely rapidly.

The behaviour of solid support materials was discussed by T. Johns (Beckman Instruments), and E. A. Hinkle and S. E. J. Johnsen (Monsanto Chemical Company, Texas City) showed how peak areas (using a thermistor detector) could be converted to molas concentrations by the use of vapour densities as correcting factors. C. S. G. Phillips (Oxford) described work using metal salts (in particular, zinc and copper stearates and nickel oleate) as column liquids. $\mathrm{H}_{\theta}$ pointed out that the strong forees between metal atoms and the ligand (solute) molecules made possible new types of separation. Changes in relative retention times up to several thousandfold in favourable cases (as, for example, with amines) could be obtained by this method. Such changes were also of value for the characterization of solute substances. He showed how the results with the metal salts columns could be related to studies of complex ion formation in aqueous solution, and how gas chromatography might thus be used for studying complexing equilibria. The use of gas chromatography in kinetic studies of the isomerization of geometrical isomers, the thermal decomposition of acetylene and the thermal decomposition of light hydrocarbons was discussed by L. F. Hatch (University of Texas), and in the study of the hydrogenation products of benzene by R. E. Rippere (General Electric Co.).

H. R. Felton (du Pont, Wilmington, Delaware) described a novel and compact high-temperature gas chromatography unit, in which the detector was a thermal conductivity cell using model-aeroplane glowplugs. Sensitivity and response data for the unit were given from $40^{\circ} \mathrm{C}$. to $550^{\circ} \mathrm{C}$, and its use was illustrated by analyses of the fluorossters of camphoric acid (boiling points $320^{\circ}$ C. $-460^{\circ}$ C.), the $\alpha$ - and $\beta-\mathrm{N}$-phenylnaphthylamines and the toluene isocyanates. The factors affecting the selection of thermistors for use in katharometers formed the subject of a useful study by P. H. Stirling and C. B. Cowan (Canadian Industries, McMasterville, Quebec), who stressed the importance of matching thermistors for resistance, resistance change with temperature and for dissipation constant. A copper oxide com. bustor as a means for increasing detector response was discussed by S. Norem (Perkin-Elmer).

One session and an invited lecture by B. O. Ayers (Phillips Petroleum) were devoted to the use of gas chromatographic instrumentation for continuous automatic analysis. Two commercial instruments (Perkin-Elmer and Leeds-Northrup) were described in some detail in the contributed papers. Ayers pointed out that a number of analysers were now available commercially, and that these instruments compared most favourably with other types of automatic analysers, especially in the wealth of data which they make available at a relatively low cost for the instrument. $\mathrm{He}$ described the testing of the Perkin-Elmer instrument on typical plant problems.

In a stimulating and entortaining after-dinner speech, A. J. P. Martin described his early work on separation techniques, in association with R. L. M. Synge and later with A. T. James, which led up to the discovery of gas-liquid chromatography. He commented on present trends in the field, the influence of gas chromatography on other techniques and its many possible applications. He concluded with some suggestions for the future of the method, including the development of the completely automatic analyst. C. S. G. Phillips

\section{MACROMOLECULAR CHEMISTRY}

\section{INTERNATIONAL SYMPOSIUM}

$T$ HE Macromolecular Commission of the International Union of Pure and Applied Chemistry broke entirely new ground this year by holding the tenth Symposium, on "Macromolecular Chemistry", in Prague. The success of this penetration into Central Europe and, for the Western countries, behind the Iron Curtain, is reflected in the record number of active participants housed in the Hotel International in the outskirts of the city in which the meetings, except for the opening session, were also held. This procedure lent an air of informality to the proceedings and, by keeping all participants in intimate contact with one another, fostered a feeling of friendly co-operation throughout the week.

No praise is high enough for the diligence, care and thoroughness with which the Organizing Committee, under the leadership of Prof. O. Wichterle, had laid its plans. Almost all the 200 papers and lectures were available in preprint form (Russian and Czech manuscripts were translated into English). To overcome the language difficulty still further, a very efficient cabinet translation service was in continuous session during the presentation of lectures and papers. All delegates were supplied with 10-channel transistor receiver head-sets which carried the translation service in Czech, Russian, French, English and German. This very fine piece of organization was much appreciated by all who took part and removed most of the strain of following complicated argument in a foreign tongue.

The matter of the Symposium was divided into two large sections dealing with $(a)$ physics and physical chemistry of macromolecules and $(b)$ polyreactions. These broad units were subdivided into smaller sections each dealing with a group of related problems in the field. The proceedings were initiated with a lecture by Prof. Paul Doty on "Biological Polymers". 